Thorax (1974), 29, 673.

\title{
Central haemodynamics during oxygen breathing in angina pectoris
}

\author{
H A R R Y LECER OF \\ Department of Clinical Physiology, Malmö General Hospital, S-214 01, Malmö, Sweden
}

\begin{abstract}
Lecerof, H. (1974). Thorax, 29, 673-677. Central haemodynamics during oxygen breathing in angina pectoris. The haemodynamic effects of breathing $100 \%$ oxygen have been studied by right heart catheterization at rest and during bicycle exercise in nine male patients with coronary heart disease. Oxygen breathing produced no significant haemodynamic benefit during angina pectoris induced by physical exercise, although at rest a reduction in heart rate and cardiac index was evident. The favourable effects of $100 \%$ oxygen breathing described in pacing-induced angina pectoris cannot therefore be transferred to exercise-induced angina probably because the myocardial blood flow during the latter condition is hampered by an increased left ventricular end-diastolic pressure.
\end{abstract}

Angina pectoris is thought to arise from hypoxia of the myocardium caused by a temporary discrepancy between the oxygen supply and demand (Keefer and Resnik, 1928; Friedberg, 1966; Harrison and Reeves, 1968). Oxygen breathing ought to increase the pain threshold in angina pectoris provided this form of treatment effects an increased supply of oxygen to the myocardium. On the other hand, hyperoxygenation has been shown to reduce tissue blood flow as a result of an increase in the precapillary sphincter tone (Martini and Honig, 1969). An attempt to improve tissue oxygenation by increasing the arterial oxygen tension may thus be counterbalanced by a reduction in blood flow on account of the pharmacological effects of oxygen (Thomas, 1968). Russek, Regan, and Naegele (1950) did not find any beneficial effect of oxygen breathing on the pain threshold in exercise-induced angina pectoris. On the other hand, Horvat et al. (1972) recently demonstrated a favourable effect of oxygen breathing on the pain threshold in angina pectoris induced by atrial pacing. With these seemingly incompatible findings in mind we examined the effects of oxygen breathing on the central haemodynamics in patients with coronary heart disease at rest as well as during angina pectoris induced by exercise.

\section{SUBJECTS AND METHODS}

Nine male patients between 46 and 59 years of age were studied. All had typical clinical, electrocardiographic, and coronary angiographic signs of coronary heart disease. The average exercise tolerance in the upright position was $475 \pm 175 \mathrm{kpm} / \mathrm{min}$ and in the supine position was
$311 \pm 122 \mathrm{kpm} / \mathrm{min}(\mathrm{kpm}=$ kilopondmeter, $100 \mathrm{kpm} /$ $\min =16 \mathrm{~W}$ ). The difference: $170 \mathrm{kpm} / \mathrm{min}$ agrees with previous observations (Lecerof, 1971). Six patients were studied as a part of a preoperative evaluation before undergoing surgery aimed at improving their myocardial blood supply. Three patients were studied as part of a postoperative evaluation one year after internal mammary implantation (Vineberg, 1946). None of the patients had signs of congestive heart failure, rheumatic heart disease or hypertension. The investigations were made in the morning when the patients were in the postabsorptive basal state. Right heart catheterization was performed with a double lumen catheter and the brachial artery was catheterized using a percutaneous technique. Cardiac output was measured by the indicator dilution technique using bromsulphalein (Wassén, 1956) injected into the right atrium via a separate catheter. Capacitance transducers (EMT 34) and a Mingograph 81 (Siemens-Elema AB, Stockholm, Sweden) were used for recording the pressures. The patients were studied in the supine position. Exercise tests were performed on a bicycle ergometer (Siemens-Elema AB, Stockholm, Sweden). Arterial pH, oxygen, and carbon dioxide tensions were measured with conventional electrodes (Instrumentation Laboratory Inc., Boston, Mass., USA) and oxygen contents were calculated from the Severinghaus' nomogram (Severinghaus and Bradley, 1958) with corrections made for physically dissolved oxygen. Vascular resistances were calculated according to the following formulae, expressed in arbitrary units:

Pulmonary vascular resistance $(\mathbf{P V R})=\frac{\mathbf{P}_{\mathbf{P A}}-\mathbf{P}_{\mathbf{P C V}}}{\mathbf{Q}}$ Systemic vascular resistance $(\mathbf{S V R})=\frac{\mathbf{P}_{\mathbf{B A}}}{\mathbf{Q}}$

(abbreviations as in Table I). 
Left ventricular stroke work index per minute (LVSWI $\mathrm{Iin}_{\text {min }}$ was calculated according to the following formula, expressed in $\mathrm{kgm} / \mathrm{min} / \mathrm{m}^{2} \mathrm{BSA}$ :

LVSWI $_{\text {min }}=\frac{\text { HR } \times \text { SVI }\left(\mathbf{P}_{\mathrm{BA}}-\mathbf{P}_{\mathrm{PCV}}\right) \times 13.6}{1000}$

The patients were first examined at rest and then during an exercise test that provoked tolerable angina pectoris. When the exercise test was completed, the patients were allowed to rest for 1 hour. The patients were then examined again at rest and the exercise test was repeated at the initial work load. Air or oxygen breathing preceded the measurements at rest for at least 20 minutes and was continued throughout the exercise test. Alternate patients started with either air of oxygen breathing.

\section{RESULTS}

AT REST As is evident from Table I, oxygen breathing at rest caused a decrease in heart rate $(d=-6.3$ beats $/ \mathrm{min}, \mathrm{P}<0.01)$ and cardiac index $(\bar{d}=-0.5$ $1 / \mathrm{min} / \mathrm{m}^{2}$ body surface, $\left.\mathrm{P}<0.05\right)$. The pulmonary artery pressure, the mean capillary venous pressure, and the pulmonary vascular resistance were unchanged, as were the mean systemic arterial pressure and the systemic vascular resistance. In spite of reductions in heart rate and cardiac index no significant reduction in the LVSWI $_{\text {min }}$ was found. Oxygen breathing affected the blood gases and $\mathrm{pH}$ at rest in the following way. The arterial $\mathrm{O}_{2}$-tension rose to an average of $604 \mathrm{mmHg}$. In mixed venous blood a conspicuous increase of oxygen tension was observed $(\mathrm{d}=8.9 \mathrm{mmHg}, \mathrm{P}<0.001)$ with a slight decrease in $\mathrm{pH}(\mathrm{d}=-0.02, \mathrm{P}<0.05)$, while the carbon dioxide tension did not change significantly.

DURING EXERCISE No significant changes of heart rate or cardiac index were recorded and, except for a slight reduction of the systemic arterial blood pressure, no haemodynamic changes were observed during exercise with oxygen breathing as compared to air breathing. The arterial oxygen tension rose to $587 \mathrm{mmHg}$ during oxygen breathing, while the arterial carbon dioxide tension showed a slight increase $(\mathrm{d}=3.9 \mathrm{mmHg}, \mathrm{P}<0.05)$, but the $\mathrm{pH}$ remained unchanged. In mixed venous blood an $\frac{C}{\sigma}$ increase of oxygen tension was seen $(\bar{d}=6.6 \mathrm{mmHg}$, $\overline{\bar{S}}$ $P<0.001)$ as well as an increase of carbon dioxide tension $(\bar{d}=5.1 \mathrm{mmHg}, \mathrm{P}<0.05)$ and a decrease of $\mathrm{pH}(\mathrm{d}=-0.03, \mathrm{P}<0.05)$.

Seven out of nine patients experienced chest pain $\vec{\circ}$ at identical levels of exercise irrespective of inhala- $\vec{\overrightarrow{ }}$ tion of air or pure oxygen. Two patients who breathed $\vec{\omega}$ oxygen at the second exercise period managed another $150 \mathrm{kpm} / \mathrm{min}$ for three to four minutes before characteristic chest pain developed.

\section{DISCUSSION}

Catheterization studies in angina pectoris usually $\stackrel{ }{\rightarrow}$ demonstrate abnormal left ventricular function $z$ (Cohn and Gorlin, 1972). The rise in left ventricular $\stackrel{<}{<}$ filling pressure with subnormal increases in stroke $\frac{\mathbb{D}}{3}$ volume and cardiac output had by some authors been interpreted as signs of left ventricular failure (Müller and Rörvik, 1958; Malmborg, 1965; Parker, $\vec{v}$

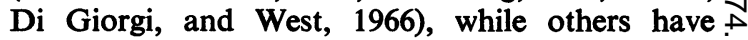
claimed a change of left ventricular compliance as a consequence of myocardial ischaemia (Wiener, Dwyer, and Cox, 1968; Linhart et al., 1969). In patients with clinical evidence of left ventricular failure oxygen breathing has been shown to 응 diminish cardiac work at rest due to reduced heart rate and cardiac output (Daly and Behnke, 1963).

In the present study a reduction in heart rate and cardiac output was found during oxygen breathing at rest. Since the arterial blood pressure and the systemic vascular resistance remained unchanged, cardiac work ought to be reduced. Although $a_{\sigma}$ decrease in LVSWI $_{\min }$ was found in five of eight 3 . patients, this decrease was not statistically significant.

In normal individuals an increase in systemico arterial pressure due to vasoconstriction is usually observed during oxygen breathing (Daly and Bondurant, 1962; Eggers, Paley, Leonard, and

T A B L E I

EFFECTS OF OXYGEN BREATHING ON HAEMODYNAMICS AT REST

\begin{tabular}{|c|c|c|c|c|c|c|c|c|c|c|}
\hline & $\underset{\text { (beats/min) }}{\text { HR }}$ & $\underset{\left(\mathrm{ml} / \mathrm{m}^{2}\right)}{\mathrm{SVI}}$ & $\underset{\left(1 / \mathrm{min} / \mathrm{m}^{2}\right)}{\mathrm{CI}}$ & $\underset{(\mathrm{ml} / \mathrm{l})}{(\mathrm{a}-\mathrm{v}) \mathrm{O}_{\mathbf{s}} \text {-diff. }}$ & $\underset{(\mathbf{m m H g})}{\text { PrCV }_{\text {m }}}$ & $\underset{(\mathbf{m m H g})}{\mathbf{P}_{\mathbf{P A}}}$ & $\underset{(\mathrm{mmHg})}{\mathbf{P}_{\mathrm{BA}}}$ & PVR & SVR & $\underset{\left(\mathrm{kgm} / \mathrm{min} / \mathrm{m}^{2}\right)}{\operatorname{LVSWI}}$ \\
\hline $\begin{array}{l}\mathbf{R} \\
\mathbf{n} \\
\mathrm{d} \\
\mathbf{S D} \\
\mathbf{P}\end{array}$ & $\begin{array}{c}66.5 \\
9 \\
-6.3 \\
5.5 \\
<0.01\end{array}$ & $\begin{array}{c}47 \cdot 9 \\
8 \\
-3 \cdot 3 \\
9 \cdot 7 \\
\text { ns }\end{array}$ & $\begin{array}{rl} & 3.2 \\
8 & \\
-0.5 & 0.6 \\
< & 0.05\end{array}$ & $\begin{array}{l}46 \cdot 6 \\
9 \\
5 \cdot 7 \\
11 \cdot 2 \\
\text { ns }\end{array}$ & $\begin{array}{c}7 \cdot 9 \\
9 \\
-0 \cdot 2 \\
3 \cdot 2 \\
\text { ns }\end{array}$ & $\begin{array}{c}13 \cdot 3 \\
9 \\
-1 \cdot 8 \\
0 \cdot 1 \\
\mathrm{~ns}\end{array}$ & $\begin{array}{c}104 \\
9 \\
0 \cdot 1 \\
0 \cdot 2 \\
\text { ns }\end{array}$ & $\begin{array}{c}0.9 \\
8 \\
-0.1 \\
3.8 \\
\text { ns }\end{array}$ & $\begin{array}{c}16 \cdot 8 \\
8 \\
3 \cdot 1 \\
3 \cdot 8 \\
\text { ns }\end{array}$ & $\begin{array}{c}41 \cdot 7 \\
8 \\
-5 \cdot 5 \\
9 \cdot 2 \\
\text { ns }\end{array}$ \\
\hline
\end{tabular}

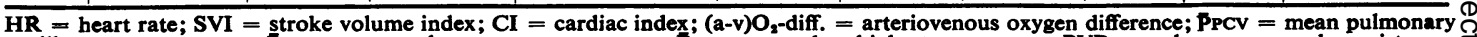
capillary venous pressure; $\mathbf{P}$ PA $=$ mean pulmonary artery pressure; $\mathbf{P}$ BA $=$ mean brachial artery pressure; $\mathbf{P V R}=$ pulmonary vascular resistance; $\bar{P}$ $\mathbf{S V R}=$ systemic vascular resistance; LVSWImin = left ventricular stroke work index per minute; $\mathbb{X}=$ mean value during air breathing; $\bar{d}=Q$ mean difference during oxygen breathing; $S D=$ standard deviation of the mean difference; $P=$ probability of the difference; ns $=$ not significant. $\sigma$ 
Warren, 1962). In patients with hypertension, however, no effect of oxygen breathing on systemic vascular resistance was found (Hillestad and Andersen, 1972), a finding explained on the basis of a postulated metabolic type of vascular fault. Related vascular changes might be responsible for the absence of a rise in arterial blood pressure at rest during oxygen breathing in the present study.

During exercise the slowing effect of oxygen on the heart rate, evident at rest, was eliminated probably by the influence of metabolic and neurogenic factors. Except for a slight reduction of the mean arterial blood pressure no significant haemodynamic changes were induced by oxygen breathing during exercise.

Oxygen breathing produced a distinct effect on the arterial oxygen tension which means that the capillary-tissue $\mathrm{O}_{2}$-gradient increased considerably. The increase of oxygen tension in mixed venous blood recorded in this study agrees with earlier observations made by Daly and Behnke (1963) and Karetzky, Keighley, and Mithoefer (1971).

In spite of a rise in physically dissolved oxygen of approximately $15 \mathrm{ml} / \mathrm{l}$ at an arterial oxygen tension of $600 \mathrm{mmHg}$, the arteriovenous oxygen difference did not change significantly. No change in total oxygen transport calculated from the product of cardiac output and arteriovenous oxygen difference was observed during oxygen breathing either at rest or during exercise. These results agree well with earlier observations in normal subjects as well as in patients with heart disease (Storstein, 1952; Andersen and Hillestad, 1970).

This study was not primarily designed to measure the pain threshold during oxygen breathing compared to air breathing. However, in the majority of patients chest pain occurred at identical work loads irrespective of inhalation of air or pure oxygen. Previous investigations have shown contradictory results as regards the influence of oxygen breathing on the pain threshold of angina pectoris during exercise. In one study, exercise tolerance was improved in 11 out of 17 patients (Riseman and Brown,
1939). In another 'all the patients appeared to tolerate the exercise better and decrease of STsegment depression was noticed in nine of twelve cases' (Pons and Berg, 1961). On the other hand, an unchanged pain threshold with unaltered intensity and frequency of angina pectoris was registered during oxygen breathing by Russek et al. (1950) and an aggravation of ischaemic ST-T changes was observed. An increased pain threshold during oxygen breathing and increased left ventricular oxygen uptake have recently been reported in angina pectoris induced by atrial pacing (Horvat et al., 1972). However, atrial pacing is an artificial way of provoking angina pectoris in which many of the haemodynamic changes accompanying angina pectoris induced by exercise are missing (Bahler and MacLeod, 1971; Holmberg and Varnauskas, 1971). For instance, angina pectoris induced by atrial pacing is usually accompanied by an unchanged or subnormal left ventricular end-diastolic pressure (LVEDP) (Bahler and MacLeod, 1971; McCans and Parker, 1973). The variability of changes in LVEDP in connection with pacinginduced angina has, however, been stressed (Chandraratna et al., 1973) and an elevation of $3 \mathrm{mmHg}$ of the LVEDP between a heart rate of 130 and 150 beats per minute has recently been reported (Balcon, Wilkinson, Walsh, and Rickards, 1974). In contrast, angina precipitated by exercise or occurring spontaneously is accompanied by a substantial increase in LVEDP or mean pulmonary capillary venous pressure which may attain values above $30 \mathrm{mmHg}$ (Parker et al., 1966; Roughgarden, 1966; Rosland, 1969). In the present study the mean pulmonary capillary venous pressure rose to an average $26 \mathrm{mmHg}$ during angina pectoris (Table II).

The myocardial blood flow is to a large extent determined by the pressure gradient between the coronary circulation and the myocardium during diastole (Salisbury, Cross, and Rieben, 1963). Angina pectoris is accompanied by a rise of LVEDP to about $30 \mathrm{mmHg}$ and this might reflect cessation of blood flow to certain subendocardial areas

T A B L E I I

EFFECTS OF OXYGEN BREATHING ON HAEMODYNAMICS DURING EXERCISE

\begin{tabular}{|c|c|c|c|c|c|c|c|c|c|c|}
\hline & $\underset{\text { (beats/min) }}{\text { HR }}$ & $\underset{\left(\mathrm{ml} / \mathrm{m}^{2}\right)}{\mathrm{SVI}}$ & $\underset{\left(1 / \mathrm{min} / \mathrm{m}^{2}\right)}{\mathrm{CI}}$ & $\begin{array}{c}(\mathrm{a}-\mathrm{v}) \mathrm{O}_{2} \text {-diff. } \\
(\mathrm{ml} / \mathrm{l})\end{array}$ & $\underset{(\mathrm{mmHg})}{\mathrm{PPCV}}$ & $\underset{(\mathrm{mmHg})}{\mathbf{P}_{\mathbf{P A}}}$ & $\underset{(\mathbf{m m H g})}{\mathbf{P B A}_{\mathrm{BA}}}$ & PVR & SVR & $\begin{array}{c}\text { LVSWI } \\
\left(\mathrm{kgm} / \mathrm{min} / \mathrm{m}^{2}\right)\end{array}$ \\
\hline $\begin{array}{l}\mathbf{X} \\
n \\
\mathrm{~d} \\
\mathbf{S} D \\
\mathbf{P}\end{array}$ & $\begin{array}{c}99 \cdot 1 \\
9 \\
-4 \cdot 8 \\
6 \cdot 9 \\
\text { ns }\end{array}$ & $\begin{array}{c}48 \cdot 3 \\
8 \\
1 \cdot 3 \\
10 \cdot 6 \\
\text { ns }\end{array}$ & $\begin{array}{c}4.8 \\
8 \\
-0.1 \\
0.9 \\
\text { ns }\end{array}$ & $\begin{array}{c}99 \cdot 1 \\
8 \\
-2.9 \\
12.6 \\
\text { ns }\end{array}$ & $\begin{array}{c}26 \cdot 3 \\
9 \\
-3.9 \\
10.0 \\
\text { ns }\end{array}$ & $\begin{array}{c}33 \cdot 5 \\
9 \\
-3 \cdot 4 \\
7 \cdot 1 \\
\text { ns }\end{array}$ & $\begin{array}{r}126 \\
9 \\
-4.2 \\
5.1 \\
<0.05\end{array}$ & $\begin{array}{l}0 \cdot 8 \\
8 \\
0 \\
0 \cdot 5 \\
\text { ns }\end{array}$ & $\begin{array}{c}14 \cdot 3 \\
8 \\
-0 \cdot 6 \\
3 \cdot 3 \\
n s\end{array}$ & $\begin{array}{r}68 \cdot 5 \\
8 \\
-2 \cdot 0 \\
18 \cdot 0 \\
\text { ns }\end{array}$ \\
\hline
\end{tabular}

HR $=$ heart rate; SVI = stroke volume index $\mathbf{C I}=$ cardiac index; $(\mathrm{a}-\mathrm{v}) \mathrm{O}_{\mathbf{2}}$-diff. $=$ arteriovenous oxygen difference; $\mathbf{P P C V}=$ mean pulmonary capillary venous pressure; $\mathbf{P P A}=$ mean pulmonary artery pressure $; \mathbf{P B A}_{\mathrm{BA}}=$ mean brachial artery pressure; $\mathbf{P V R}=$ pulmonary vascular resistance; $\mathbf{S V R}=$ systemic vascular resistence; LVSWImin = left ventricular stroke work index per minute; $\mathbb{X}=$ mean value during air breathing; $\mathrm{d}=$ mean difference during oxygen breathing; $\mathbf{S D}=$ standard deviation of the mean difference; $\mathbf{P}=$ probability of the difference; $n=$ not significant. 
of the myocardium. The increased amount of oxygen in the arterial blood during oxygen breathing might therefore not be transported to these ischaemic parts of the heart. Conversely the favourable effect of oxygen breathing on the pain threshold and on left ventricular oxygen consumption in pacinginduced angina reported by Horvat et al. (1972) might be explained by a more even distribution of myocardial blood flow due to the lower LVEDP in pacing-induced angina. It must, however, also be borne in mind that artificial pacing allows a better control of pulse rate and arterial pressure than the induction of angina by effort. Thus, atrial pacing may be a better method of detecting a small benefit of oxygen breathing on the pain threshold in angina pectoris.

\section{REFERENCES}

Andersen, A. and Hillestad, E. (1970). Hemodynamic responses to oxygen breathing and the effect of pharmacological blockade. Acta Medica Scandinavica, 188, 419.

Bahler, R. C. and MacLeod, C. A. (1971). Atrial pacing and exercise in the evaluation of patients with angina pectoris. Circulation, 43, 407.

Balcon, R., Wilkinson, R., Walsh, W., and Rickards, A. (1974). Criteria for the validity of the rise in left ventricular end diastolic pressure following pacing induced angina. American Journal of Cardiology, 33, 124.

Chandraratna, P. A. N., Shah, P. M., Kramer, D. H., Davis, R. J., and Schreiner, B. F. (1973). Spectrum of haemodynamic responses to atrial pacing in coronary artery disease. British Heart Journal, 35, 1033.

Cohn, P. F. and Gorlin, R. (1972). Abnormalities of left ventricular function associated with the anginal state. Circulation, 46, 1065.

Daly, W. J. and Behnke, R. H. (1963). Hemodynamic consequences of oxygen breathing in left ventricular failure. Circulation, 27, 252.

- and Bondurant, S. (1962). Effects of oxygen breathon the heart rate, blood pressure, and cardiac index of normal men - resting, with reactive hyperemia, and after atropine. Journal of Clinical Investigation, 41, 126.

Eggers, G. W. N., Jr., Paley, H. W., Leonard, J. J., and Warren, J. V. (1962). Hemodynamic responses to oxygen breathing in man. Journal of Applied Physio$\log y, 17,75$.

Friedberg, C. K. (1966). Diseases of the Heart, 3rd edition. Saunders, London.

Harrison, T. R. and Reeves, T. J. (1968). Principles and Problems of Ischemic Heart Disease. Year Book Medical Publishers, Chicago.

Hillestad, L. and Andersen, A. (1972). Hemodynamic effects of oxygen breathing in systemic arterial hypertension. Observations upon the cardiac, vascular and metabolic responses. Angiology, 23, 47.
Holmberg, S. and Varnauskas, E. (1971). Coronary circulation during pacing-induced tachycardia. Acta Medica Scandinavica, 190, 481 .

Horvat, M., Yoshida, S., Prakash, R., Marcus, H. S., Swan, H. J. C., and Ganz, W. (1972). Effect of oxygen breathing on pacing-induced angina pectoris and other manifestations of coronary insufficiency. Circulation, 45, 837.

Karetzky, M. S., Keighley, J. F., and Mithoefer, J. C. $\overrightarrow{\vec{\omega}}$ (1971). The effect of oxygen administration on gas exchange and cardiopulmonary function in normal subjects. Respiration Physiology, 12, 361.

Keefer, C. S. and Resnik, W. H. (1928). Angina pectoris. A syndrome caused by anoxemia of the myocardium. Archives of Internal Medicine, 41, 769.

Lecerof, H. (1971). Influence of body position on exercise tolerance, heart rate, blood pressure, and respiration음 rate in coronary insufficiency. British Heart Journal, $\rightarrow$ 33, 78 .

Linhart, J. W., Hildner, F. J., Barold, S. S., Lister, J. W., and Samet, P. (1969). Left heart hemodynamics $\frac{\Phi}{3}$ during angina pectoris induced by atrical pacing. Circulation, 40, 483.

Malmborg, R. D. (1965). A clinical and hemodynamic $\vec{\theta}$ analysis of factors limiting the cardiac performance $A$ in patients with coronary heart disease. Acta Medica: Scandinavica, Supplement, 426

Martini, J. and Honig, C. R. (1969). Direct measurement of intercapillary distance in beating rat heart in situ $\bar{\partial}$ under various conditions of $\mathrm{O}_{2}$ supply. Microvascular Research, 1, 244.

McCans, J. L. and Parker, J. O. (1973). Left ventricular pressure-volume relationships during myocardial $\bar{\partial}$ ischemia in man. Circulation, 48, 775 .

Müller, O. and Rörvik, K. (1958). Hemodynamic consequences of coronary heart disease: with observations during anginal pain and on the effect of nitroglycerin. British Heart Journal, 20, 302.

Parker, J. O., Di Giorgi, S., and West, R. O. (1966). A hemodynamic study of acute coronary insufficiency precipitated by exercise, with observations on the effects of nitroglycerin. American Journal of Cardio$\log y, 17,470$.

Pons, E. R., Jr. and Berg, J. L. (1961). The physiologic advantage of oxygen during exercise in patients with coronary artery insufficiency. Diseases of the Chest, 39, 551 .

Riseman, J. E. F. and Brown, M. G. (1939). The effect of N oxygen on the exercise tolerance of patients with $\mathrm{G}$ angina pectoris. American Heart Journal, 18, 150 . N

Rosland, G. A. (1969). Haemodynamic observations $N$ during spontaneous angina pectoris. British Heart 0 Journal, 31, 523.

Roughgarden, J. W. (1966). Circulatory changes associ- $\stackrel{0}{-}$ ated with spontaneous angina pectoris. American Journal of Medicine, 41, 947.

Russek, H. I., Regan, F. D., and Naegele, C. F. (1950). T One hundred per cent oxygen in the treatment of $\frac{\overrightarrow{\mathbb{D}}}{\vec{D}}$ acute myocardial infarction and severe angina $\varrho$ pectoris. Journal of the American Medical Associa- $\mathbb{Q}$ tion, 144, 373. 
Salisbury, P. F., Cross, C. E., and Rieben, P. A. (1963). Acute ischemia of inner layers of ventricular wall. American Heart Journal, 66, 650.

Severinghaus, J. W. and Bradley, A. F. (1958). Electrodes for blood $\mathrm{pO}_{2}$ and $\mathrm{pCO}_{2}$ determination. Journal of Applied Physiology, 13, 515.

Storstein, O. (1952). The effect of pure oxygen breathing on the circulation in anoxemia. Acta Medica Scandinavica, Supplement, 269.

Thomas, M. (1968). Discussion. In Smith, J., Penninckx, J. J., Kampschulte, S., and Safar, P. (1968). Need for oxygen enrichment in myocardial infarction, shock and following cardiac arrest. Acta Anaesthesiologica Scandinavica, Supplement, 29.

Vineberg, A. M. (1946). Development of an anastomosis between the coronary vessels and a transplanted internal mammary artery. Canadian Medical Association Journal, 55, 117.

Wassén, A. (1956). The use of bromsulphalein for determination of the cardiac output. Scandinavian Journal of Clinical and Laboratory Investigation, 8, 189.

Wiener, L., Dwyer, E. M., and Cox, J. W. (1968). Left ventricular hemodynamics in exercise-induced angina pectoris. Circulation, 38, 240.

Requests for reprints to: Dr. Harry Lecerof, Department of Clinical Physiology, Malmö General Hospital, S-21401, Malmö, Sweden. 